Bull. Fac. Agric., Cairo Univ., 58 (2007):112-119.

\title{
EVALUATION OF NUTRITIONAL STATUS OF SOME LEARNING DISABILITY FEMALE STUDENTS (7-14 YEARS) IN RIYADH CITY SCHOOLS
}

(Recieved:15.10.2006)

\author{
By \\ A. A. Al-Shoshan \\ Food Science and Nutrition Department, College of Food Sciences and Agriculture, King \\ Saud University, Riyadh, Saudi Arabia
}

\begin{abstract}
This study has been performed on 170 girl students having learning disability age 7-14 enrolled in general educational schools in Riyadh City to evaluate their nutritive states. To achieve this purpose a questionnaire was prepared to identify study changes of the 24 hours recall and body measures.

Food consumption has been exactly studied for the major elements such as proteins, carbohydrates, fats, vitamins and minerals by using the method of 24 hours recall. Then comparing the consumed nutritive elements with the Recommended Dietary Allowances (RDA, 1989), prepared by Food and Nutrition Association in America. Girl ages were divided according to schedules of international recommendations for different dietary allowances into two classes 7-10 years and 11-14 years. The results showed that protein consumption rate is higher than dietary recommendations of the two classes, while consumption of energy and fat were low comparing to RDA. As for vitamin consumption, the results showed that it was low for both vitamin $A$ and vitamin $B_{1}$, while it was higher than dietary recommendations for vitamin $\mathrm{C}$ and vitamin $\mathrm{B}_{2}$. As for mineral consumption, the results showed that 24 hour food provides the girls with enough amounts of phosphorous, iron, sodium comparing to RDA, while calcium was low.

Studying body measurements to evaluate nutritive case of girls through comparing height with age, it shows that $50 \%$ of girls height is lower than minimum of natural height for those of same age according to (RDA). Weight results comparing to age showed that girls have natural weight and by comparing head with age, it showed that the girls have heads bigger than natural rate and in comparing arm with age, the results showed that the girls have natural rate comparing to children of same age. Results showed $62.4 \%$ increased weight (BMI>27).

The study recommend that balanced diet should be maintained to meet the body requirements and nutritional needs.
\end{abstract}

Key words: evaluation, female students, learning disability, nutritional status, Riyadh city schools.

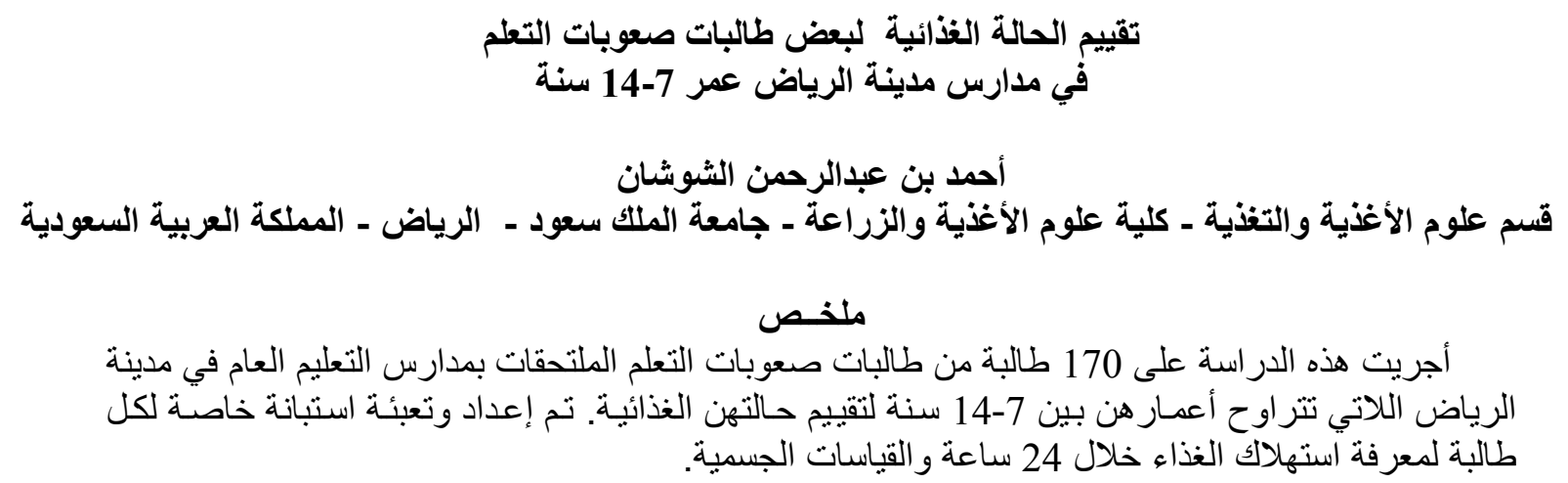




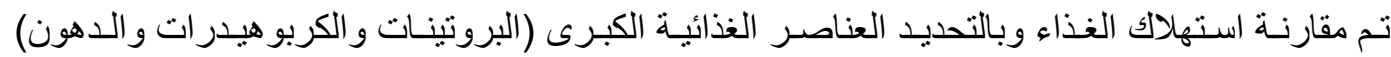

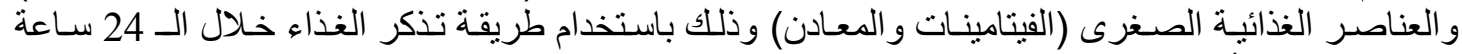
الماضية. قسمت أعمار الطالبات حسب جداول التوصيات الدولية للمقررات الغذائية المختلفة (NRC, 1989)

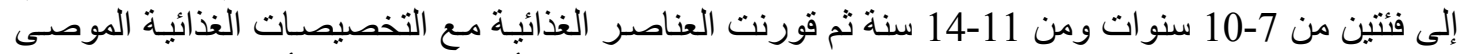

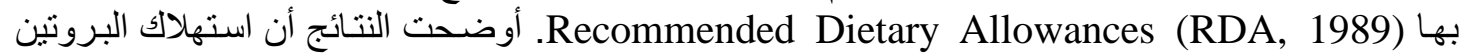

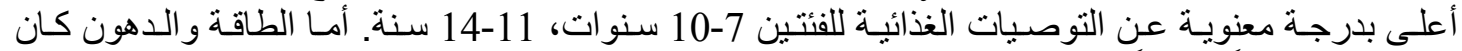

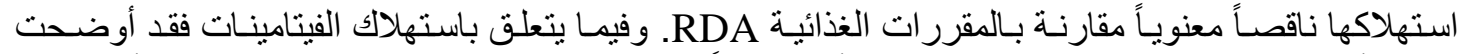

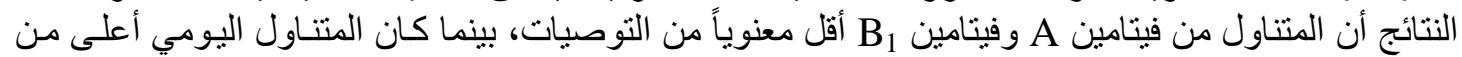

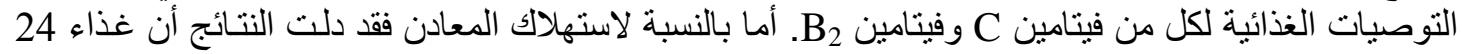

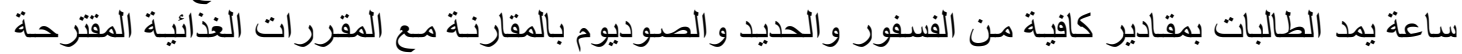

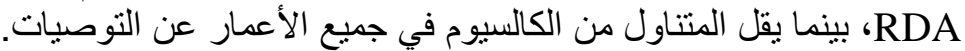

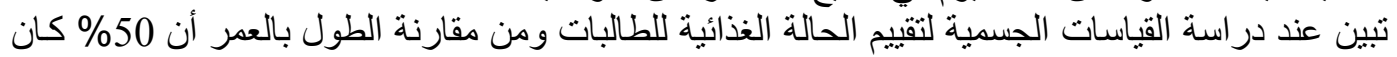

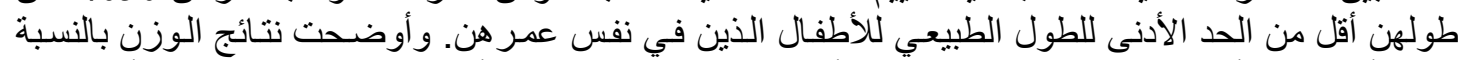

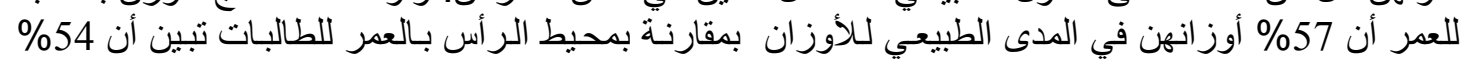

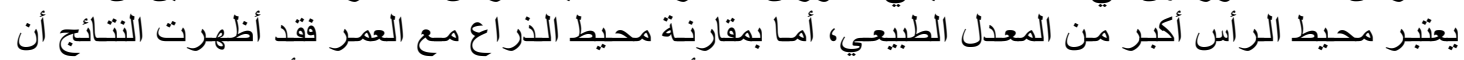

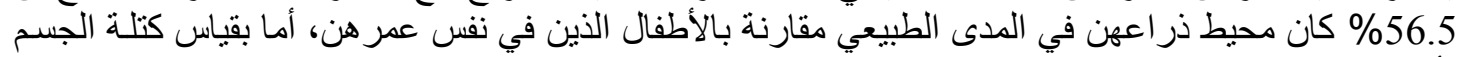

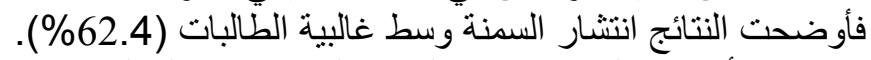

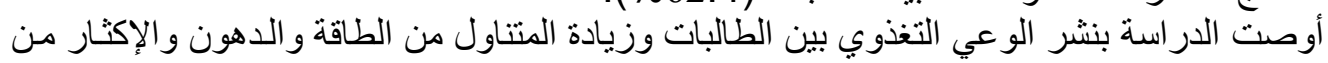

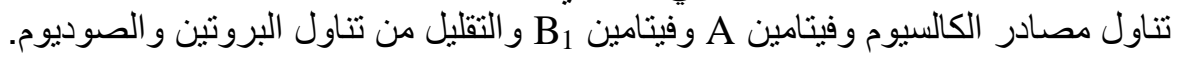

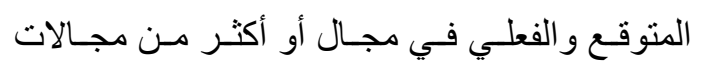

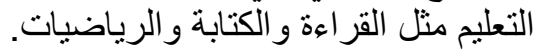

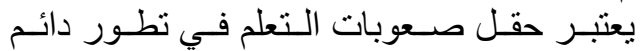

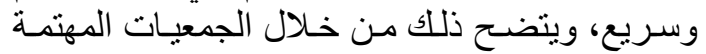

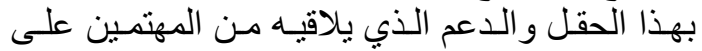

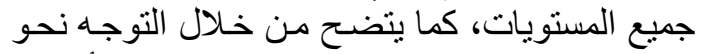

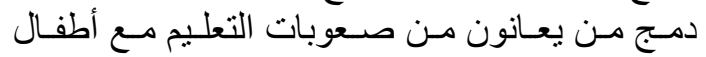

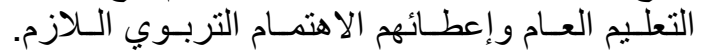

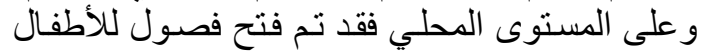

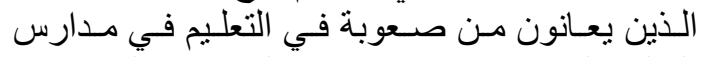

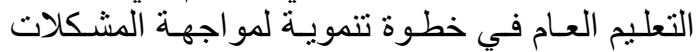
التعليمية التي تؤدي إلى تدني تحصيل خلوة الطلاب.

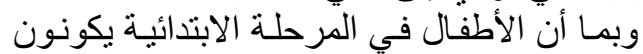

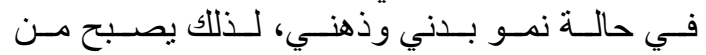

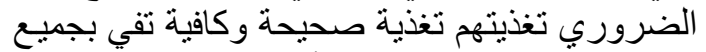

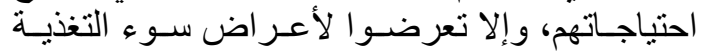

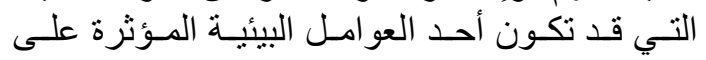

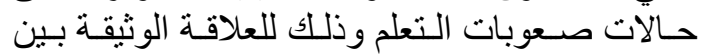

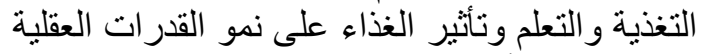

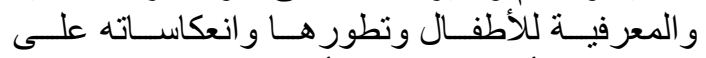

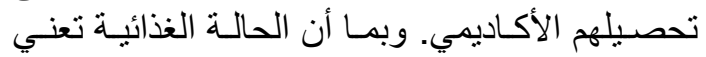

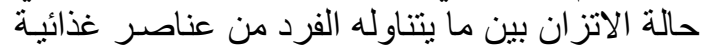

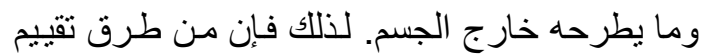

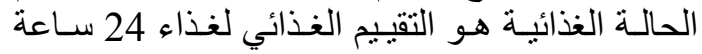

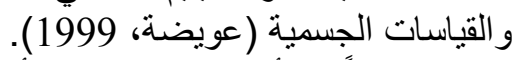

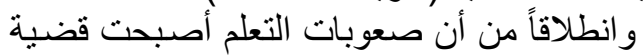

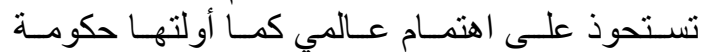

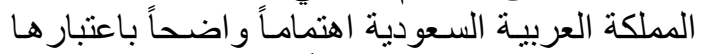

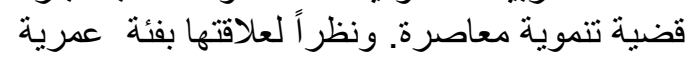

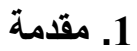

تشكل المرحلة الابتدائية حجر الزاوية في العملية

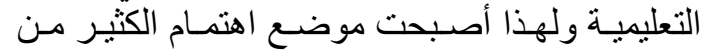

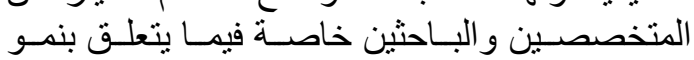

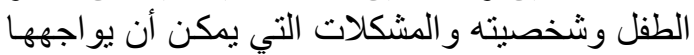

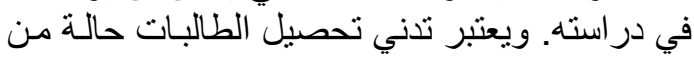

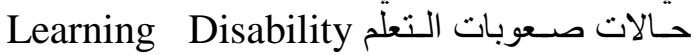
والتـي عرفتهـا اللجنـة القوميـة الاستشــارية للأطفـال

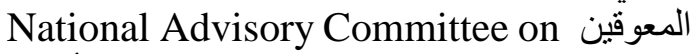
Handicapped Children (NACHC)

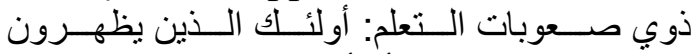
اضنطر ابات في واحد أو أكثر مـن العمليات النفسية

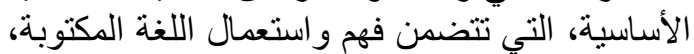

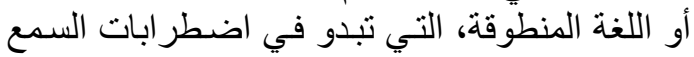

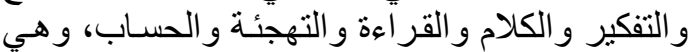
لا تعود إلى أسباب تتعلق بالإعاقة العقلية أو السمعية

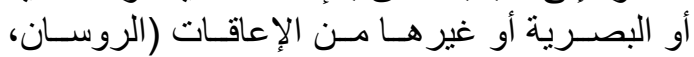

ويـرى حسـين (1992) أن صــــوبات الـتـعلم

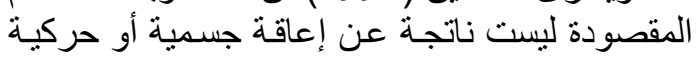

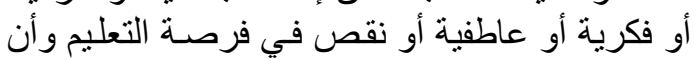
التلاميذ الذين بعانون من صعوبة التعلم، تحدث فئ لديهم

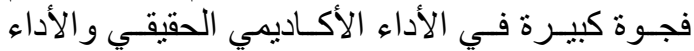

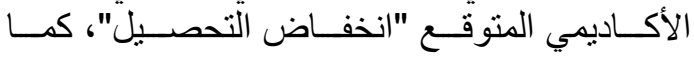

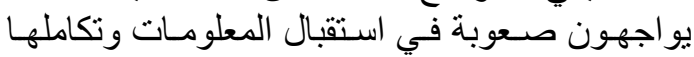

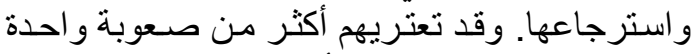

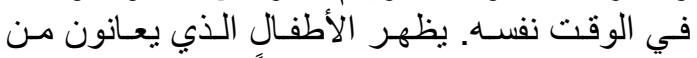

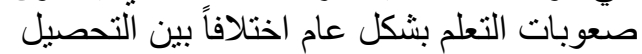




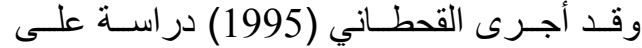

الطلاب السعوديين الذين تتر اوح أعمار هم بين 12 19- درانية

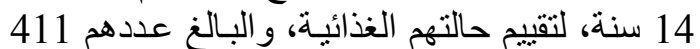

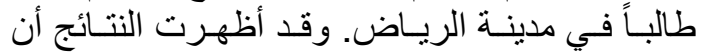

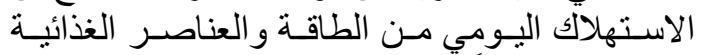

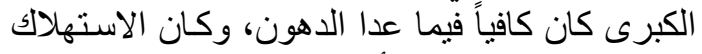

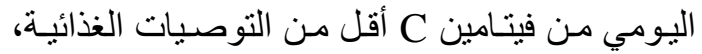

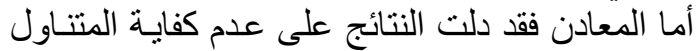
اليومي من الكالسيوم، البوتاسيوم و الماغنسيوم.

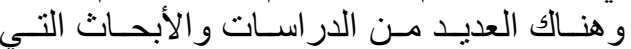

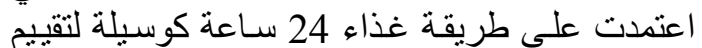
الحالة الغذائية.، في دراسة أجر اها أندجاني (1996)

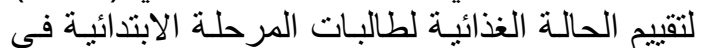

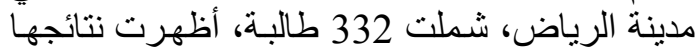

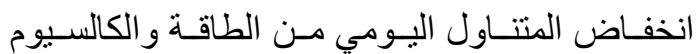

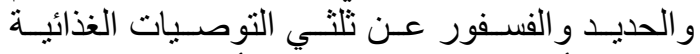

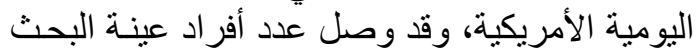

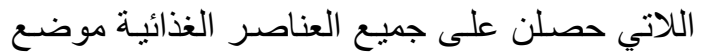
الدر اسة بكميات تتناسب و التوصيات التوني الغذائية إلى 33

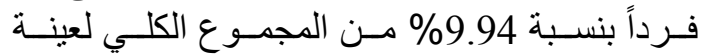

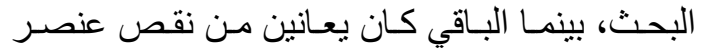
واحد أو أكثر في غذائهن اليومي.

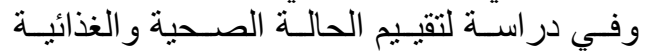
للأطفال ذوي الإعاقة العقلية البسيطة، قام بها أبوزيد

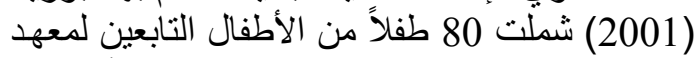

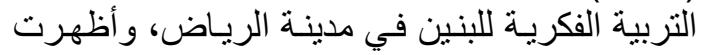

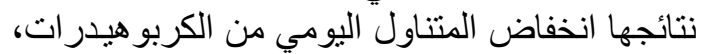

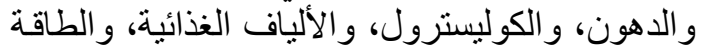

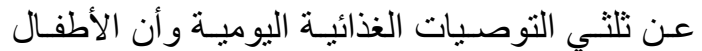

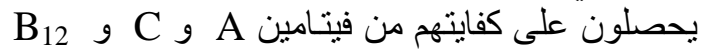

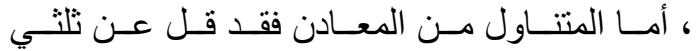
التوصيات اليومية.

\subsection{1 القياسات الجسمية}

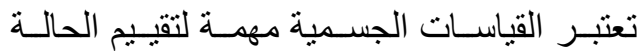

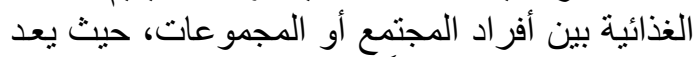

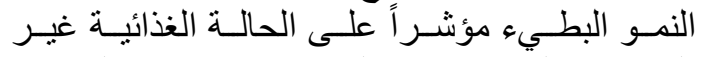

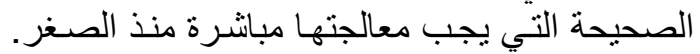

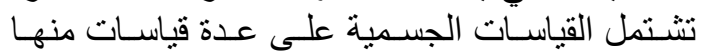
الوزن والطول ومؤشر كتلة الجسم BMI و غير هـا. وتعتبر القياسات الجسمية من الفحوص الطبية الفية الهامـة

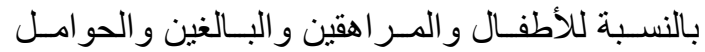

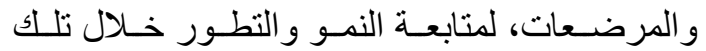
المرحلة من العمر (عويضة، لمتية 1999).

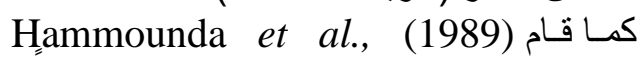

بدر اسة تناولت المقاييس الجسمية على 3762 طالباً
حساسة صحياً، ولندرة الدر اسات التي أجريت داخل

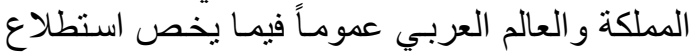
العلاقة بين التغذية ومشكلات التربـات صعوبات التعلم يأتي

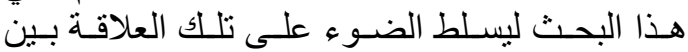
التغذية وصعوبات النعلم.

1.1. الإطار النظري والأراسات السابقة

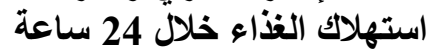
يعتبر غذاء 24 سـاعة أحد الطرق الثناء التي تستخدم

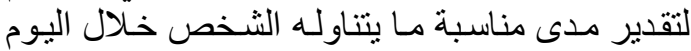

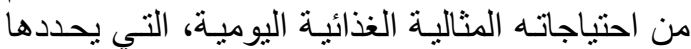

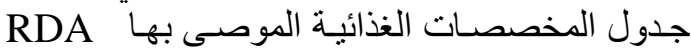
،(Recommended Dietary Allowances) وقد عرفها كل من الثبيمي والمنياوي (1988) بأنها

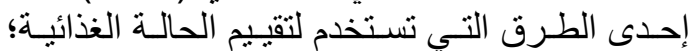
لللتعرف على ما يتتاوله الفرد خلال الفال 24 ساعة السابقة

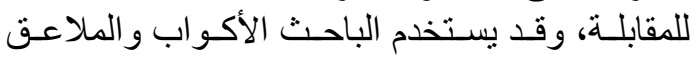

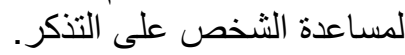

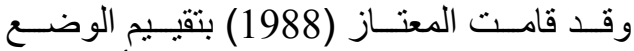

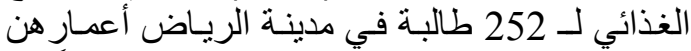

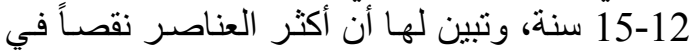

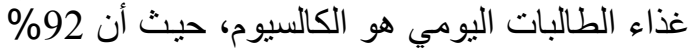

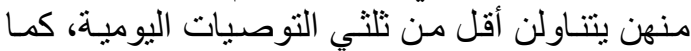

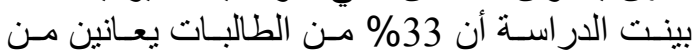

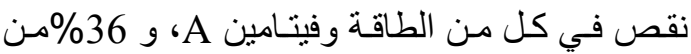

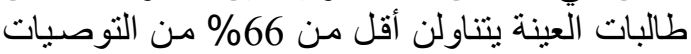

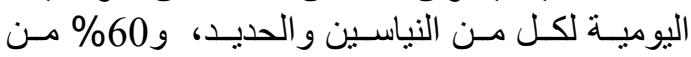

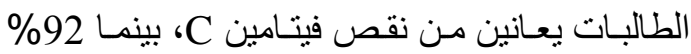

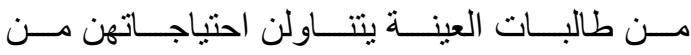

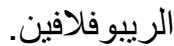

وفي در اسـة (1991) Al-Saderi لتقيقيم الحالة

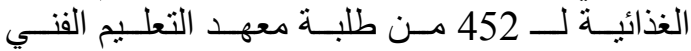
و التدريب المهني بالرياض، أظهرت النتائج أن هنالك الته

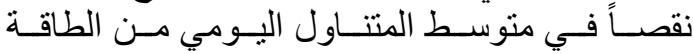

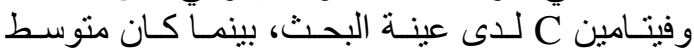
المتناول اليومي من البروتين، والدين لـانهون، و الثيامين،

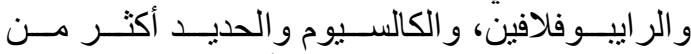

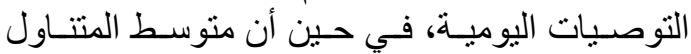
اليومي من الكربو هيدر ات وفيتامين A و الزنك وجدي التيد

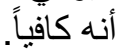
وفي دراسة البدر (1994) لتقييم الوضع الغذائي

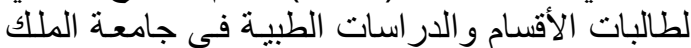

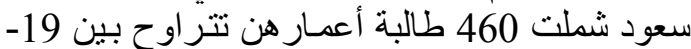

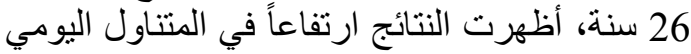

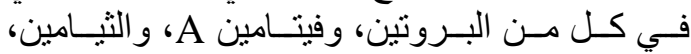

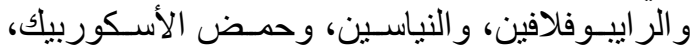

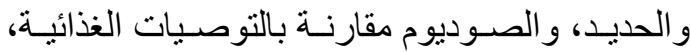

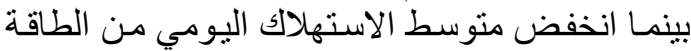

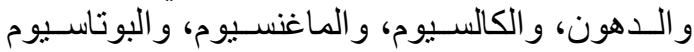

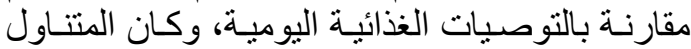
من الكربو هيدر ات و الفسفور كافياً. 


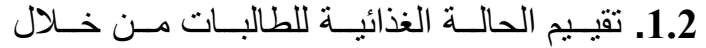

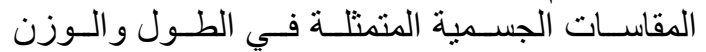
ومحيط كل من الر أس و الذر العاع. 2.2. قياس كتلة الجسم لمعرفة مدى الزعل التشـار السمنة و النحافة وسط الطالبات.

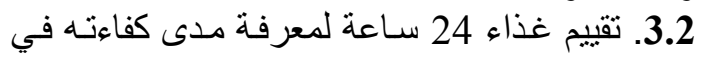

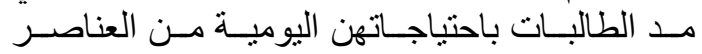
الغذائية و الطاقة.

\section{3. الطريقة البحثية}

\section{3 الثاملة و العينة}

تنطوي شاملة هذا البحث على طالبات صعوبات الرئل

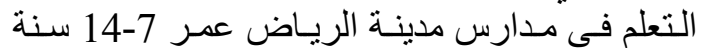

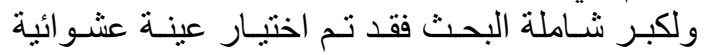
بسيطة Simple Random Sample بلغت 170 طالبة.

\section{3. جمع البيانات وتحليلها}

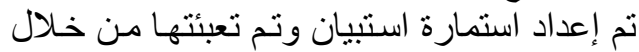

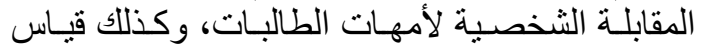
الاستهلاك الغذائي للطالبات باستخدام استمارة لقياس

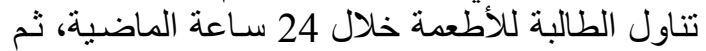

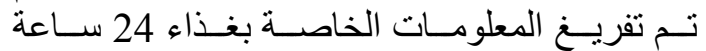

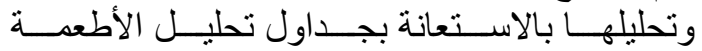
(Hamilton et al., 1988 \& Eleanor et al.,

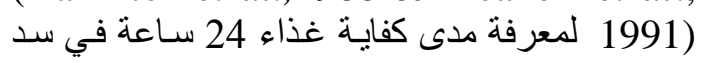

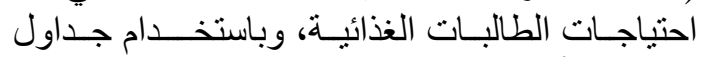

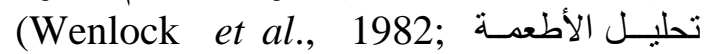
.Al-Attas and Sulimani, 1993)

\section{3.القياسات الجسمية}

و لإجر اء القياسات الجسمية نم أخذ القياسات

قياس الوزن إلى أقرب 0.5كجم باستخدام

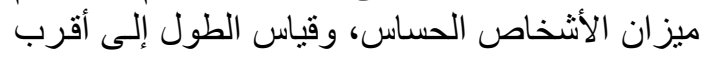

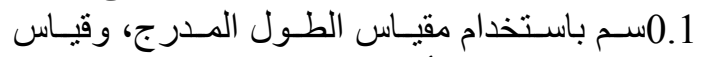

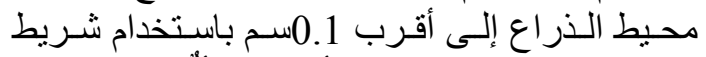

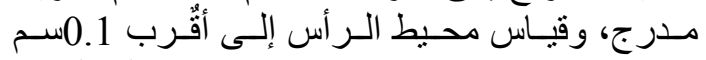

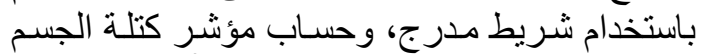

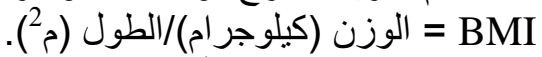

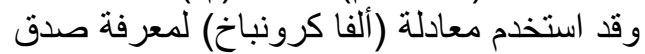

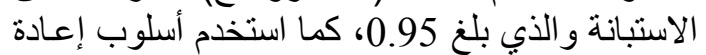

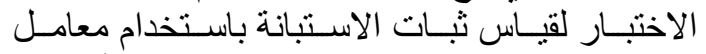

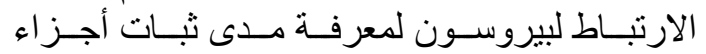

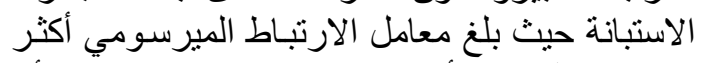

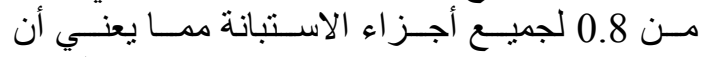

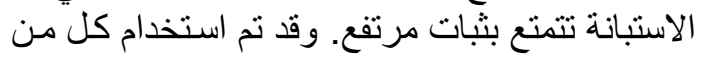

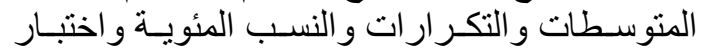

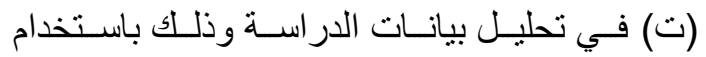

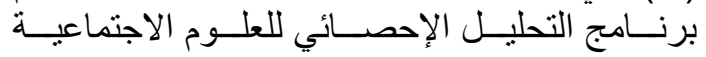
.SPSS
تتز اوح أعمار هم ما بين 6-15 سنة في المنطقة

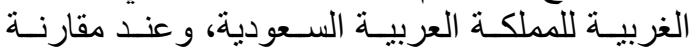

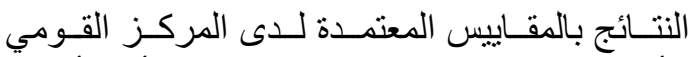

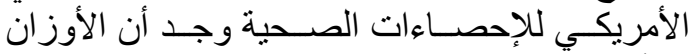

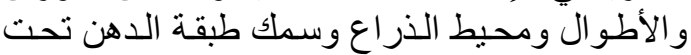

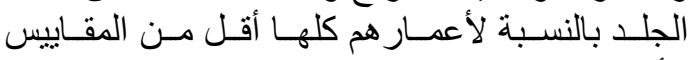

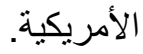

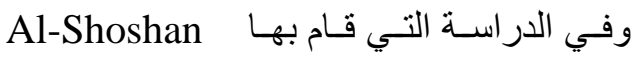

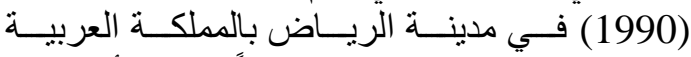

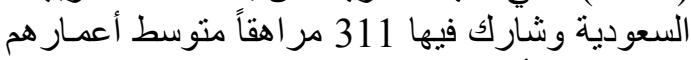

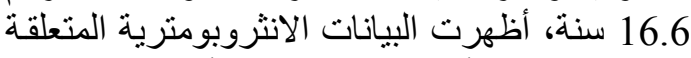

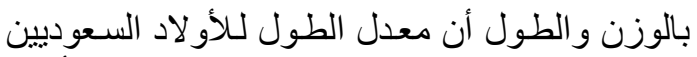

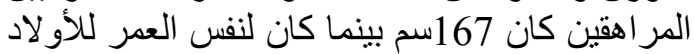

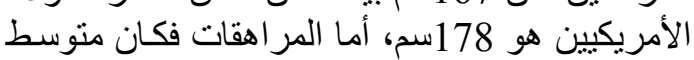

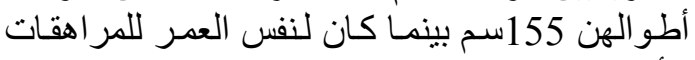
الأمريكيات 163سن.

وفي دراسـة تناولت المقاييس الجسمية أجراهـا Al-Sekait et al., (1992) على الجن 47810 من اهن

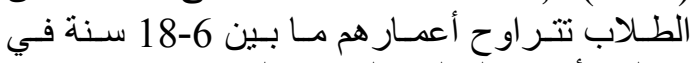

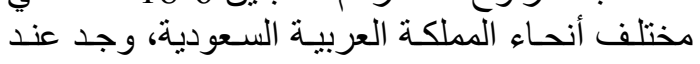

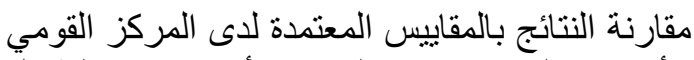

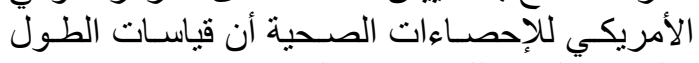

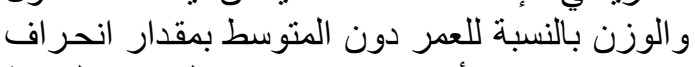

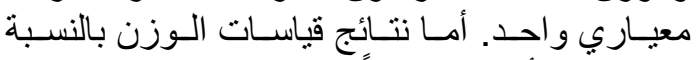

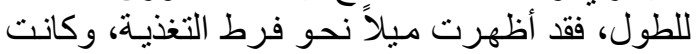
في الطالبات أعلى منها عند الطلاب. و أجرى القحطاني (1995) دراسـة لتقياتيم الحالة

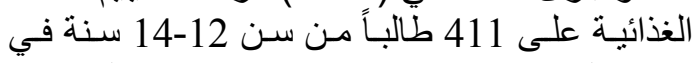

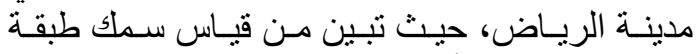
الدهن تحت الجلد أن 2.22.

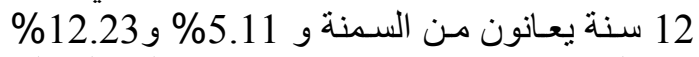

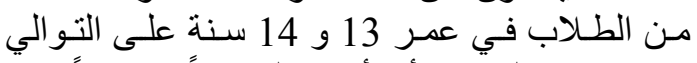

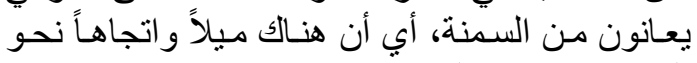

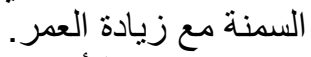

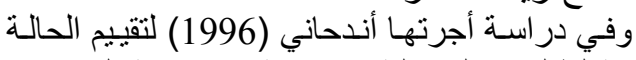

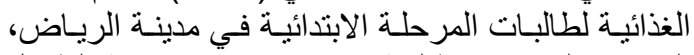

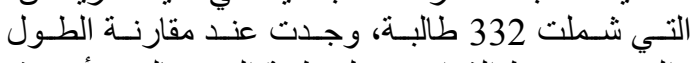
والوزن ومحيط الذراع وسمك طبقة الدهن بالعمر أن هذه

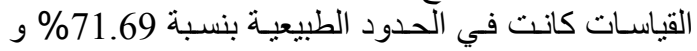

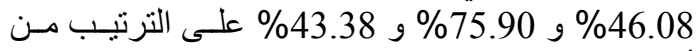
أفراد عينة البحث، وهن يتمنعن بحالة غذائية جيدة، و وعند

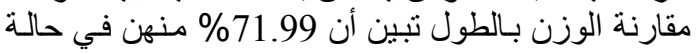
غذائية جيدة.

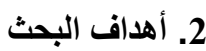

يهدف هذا البحث بصفة أساسية إلى تقيثيم الحالـة

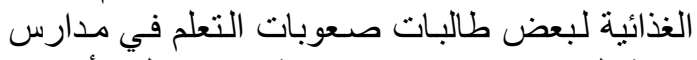

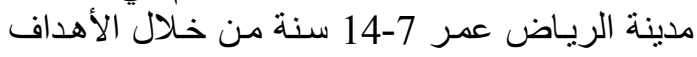
الفر عية النالية: 


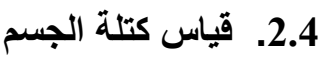

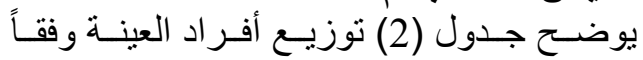

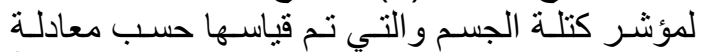
Frisancho (1993)

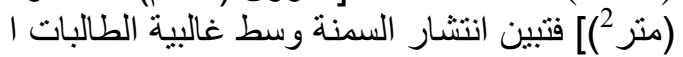

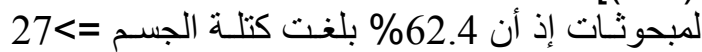
مقابل 2.9\% فقط يعانين من النحافة حيث بلغت كتألة

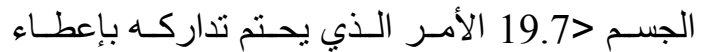

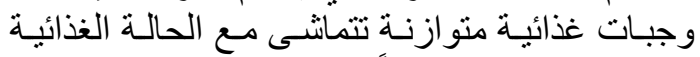
للطالبات المبحوثات وفقاً لتقييم غذاء 24 ساعة.
4. نتائج البحث ومناقشتها

1.4.المقاسات الجسمية

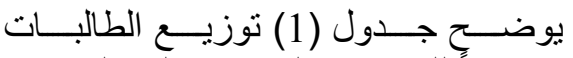

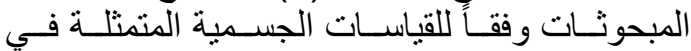

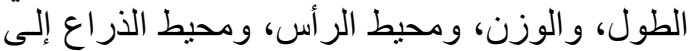

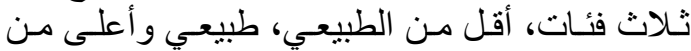

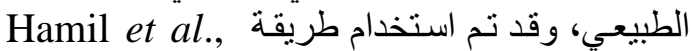
(1979) في مقارنة كل من الطول و الوزن، وطريقة

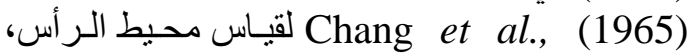
وطريقة (1993) Frisancho لقياس محيط الذراع.

جدول (1): توزيع أفراد العينة وفقاً للقياسات الجسمية (الطول، والوزن، ومحيط الرأس ومحيط الذراع).

\begin{tabular}{|c|c|c|c|c|c|c|c|c|}
\hline \multicolumn{2}{|c|}{ محيط الذراع } & \multicolumn{2}{|c|}{ محيط الر أس } & \multicolumn{2}{|c|}{ الوزن } & \multicolumn{2}{|c|}{ الطول } & \multirow[t]{2}{*}{ المستوى } \\
\hline$\%$ & عدد & $\%$ & عدد & $\%$ & عدد & $\%$ & عدد & \\
\hline 32.4 & 55 & 3.5 & 6 & 28.8 & 49 & 50.0 & 85 & أقلّ من الطبيعي \\
\hline 56.5 & 96 & 42.4 & 72 & 57.1 & 97 & 46.5 & 79 & طبيعي \\
\hline 11.1 & 19 & 54.1 & 92 & 14.1 & 24 & 3.5 & 6 & أعلى من الطبيعي \\
\hline 100.0 & 170 & 100.0 & 170 & 100.0 & 170 & 100.0 & 170 & المجموع \\
\hline
\end{tabular}

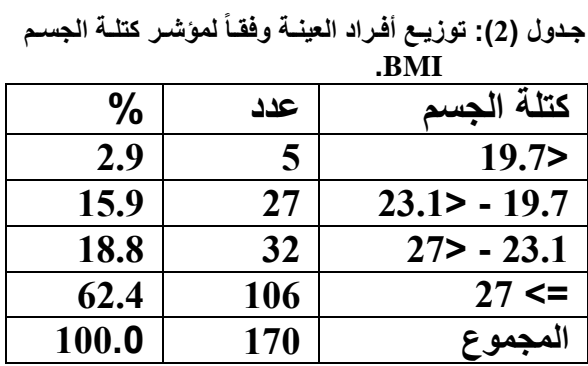

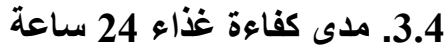

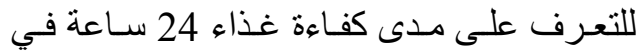

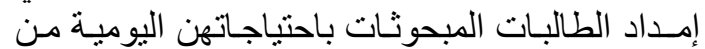

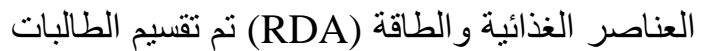

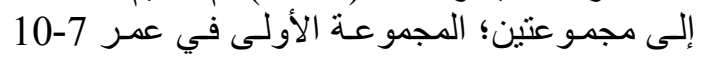

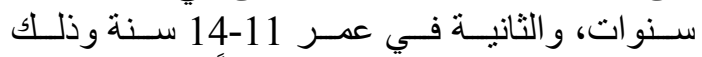

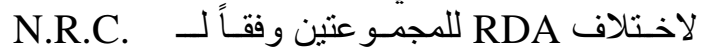

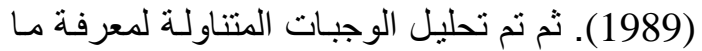

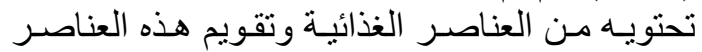

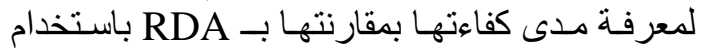
اختبار ات للبيانات الزوجية (متوسط استهلاك الطالبة لئة

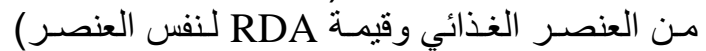

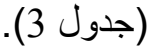

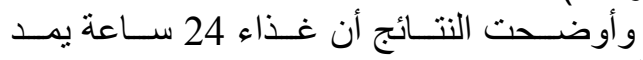

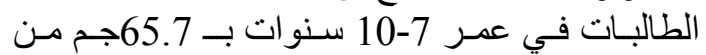

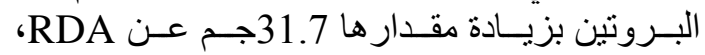

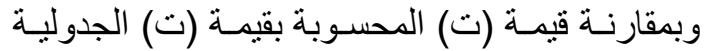

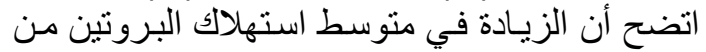
قيمة RDA ذات مغزى معنوي عند مستوى معنويـة النية

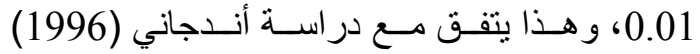

أوضحت النتائج أن نصف الطالبات المبحوثات

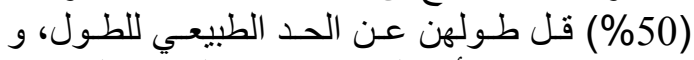

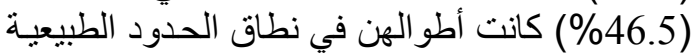

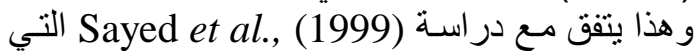

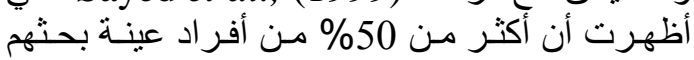

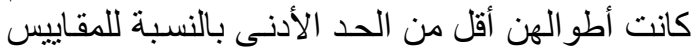

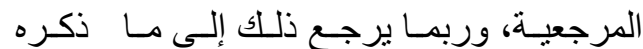
Williams and Anderson (1993)

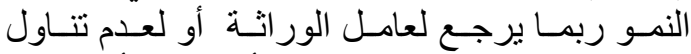
وجبات غذائية كافية لفترة طويلة أو إلى ما أثنار إليه اليه الفيه من أن أطو ال الأطفال السـوديبين

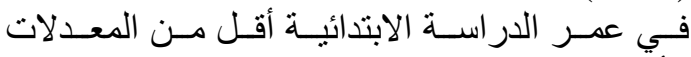

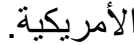

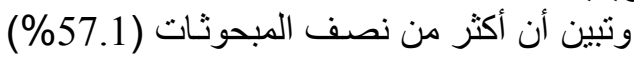

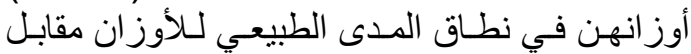
14.1\% فقط أوز انهن أعلى من الحدّ الأعلى للوزئ مقابل

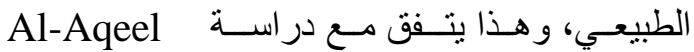

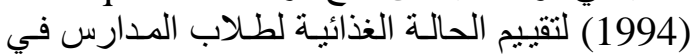
مدينة الرياض. أما بالنسبة لمقياس محيط الر أس فتبين أن أكثر من نصف المبحوثات (54.1\%) يعتبر محيط الر أس الس

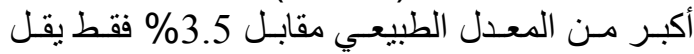

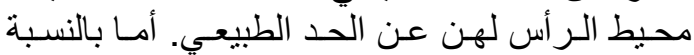

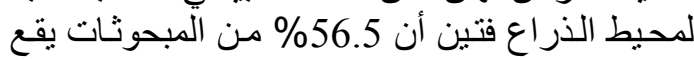

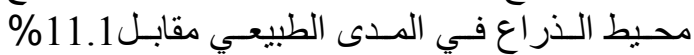
محيط الذراع لهن أكبر من الحد الطبيعي. 


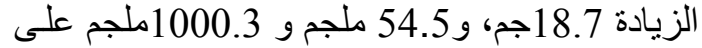

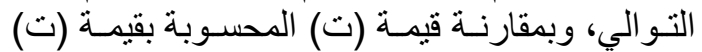

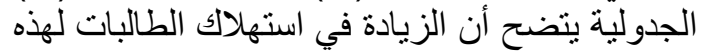

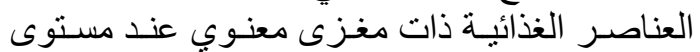

كما تبين عدم كفـاءة غذاء 24 سـاعة في إمداد

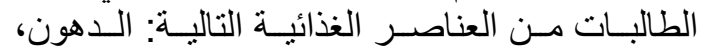

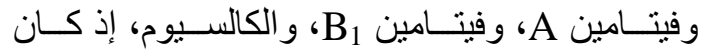
النقص في متوسط استهلاك هذه العناصر 25.6جم، أنمان
وكذللك بالنسـبة لفيتـامين C وفيتـامين B و و الفسـفور

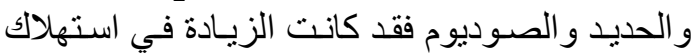

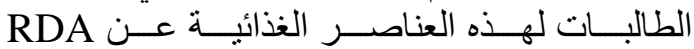

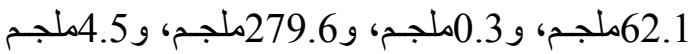

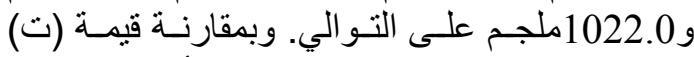

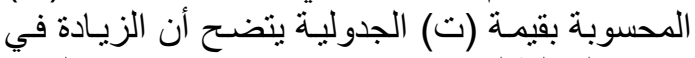

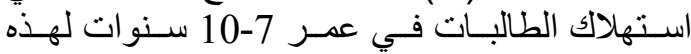

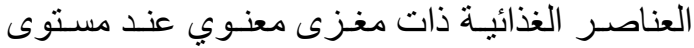
0.01

جدول (3): مقارنة متوسط الاستهلاك اليومي لأفراد العينة في عمر 7-10 سنوات من العناصر الغذائية والطاقـة

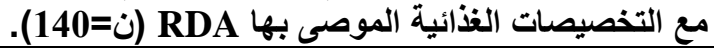

\begin{tabular}{|c|c|c|c|c|}
\hline $\begin{array}{l}\text { قيمة (ت) } \\
\text { t-value }\end{array}$ & 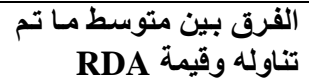 & 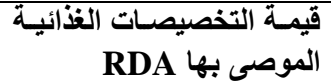 & متوسط ما تم تتاوله & الغناصر الذذائية والطاقة \\
\hline 14.1- & 400.0- & 2000.0 & 1598.1 & طاقة (سعر) \\
\hline 8.5 & 31.7 & 34.0 & 65.7 & بروتين (جم) \\
\hline $2.5-$ & 14.5- & 250.0 & 235.5 & كربو هيدرات (جم) \\
\hline 15.5- & 22.9- & 66.6 & 43.7 & دهون (جم) \\
\hline $11.7-$ & 278.8- & 700.0 & 421.1 & فيتامين A (مكافئ ريتول) \\
\hline 10.2 & 62.1 & 45.0 & 107.1 & فيتامين C (ملجم) \\
\hline 10.8- & 0.3- & 1.0 & 0.7 & فيتامين B \\
\hline 4.8 & 0.3 & 1.2 & 1.5 & فيتامين B \\
\hline $7.6-$ & $257.7-$ & 800.0 & 542.3 & كالسيوم Ca (ملجم) \\
\hline 8.1 & 279.6 & 800.0 & 1079.6 & فسفور P (ملجم) \\
\hline 5.6 & 4.5 & 10.0 & 14.5 & حديد Fe (ملجم) \\
\hline 23.6 & 1022.0 & 400.0 & 1422.0 & صوديوم Na (ملجم) \\
\hline
\end{tabular}

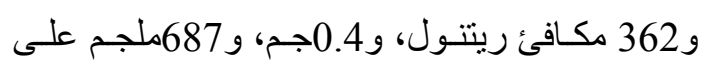

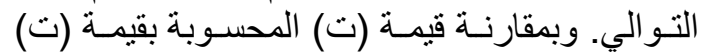
الجدولية فيتضح أن النقص في استهارلاك الطالبات من

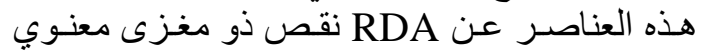

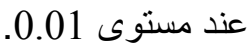

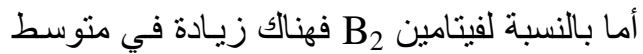

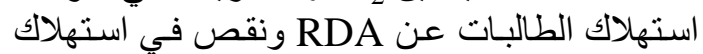

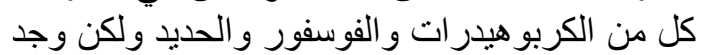

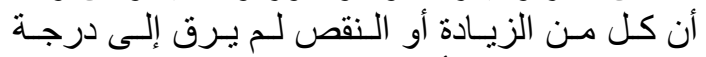

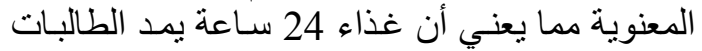

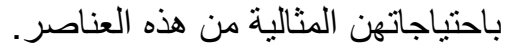

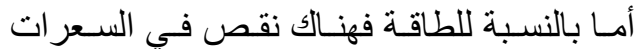
الحرارية بلغت 548.1 سعر وأن هذا النقص معنوي

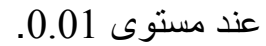

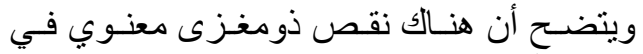

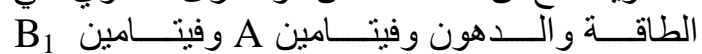

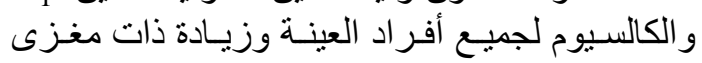

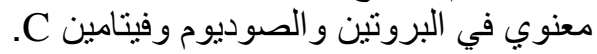

كما ثبت عدم كفاءة غذاء 24 سـاعة في إمداد

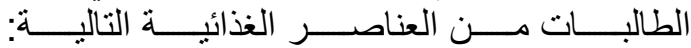

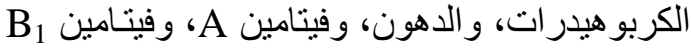

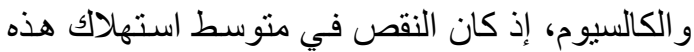

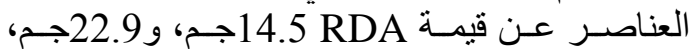

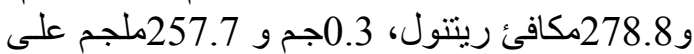

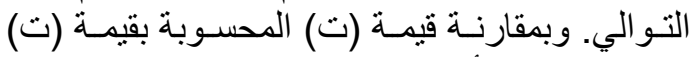
الجدولية يتضح أن النقص في استهلاك الطالبات في

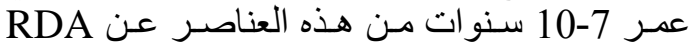
نقص ذو مغزى معنوي عند مستوى 0.1 عدان عدا النقص

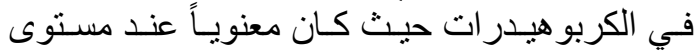
0.05 و هذا يتفق مع در اسة القحطاني (1995).

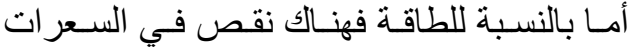

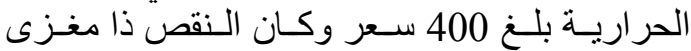

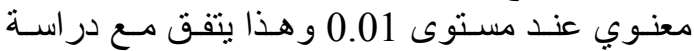

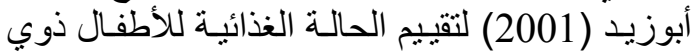
الإعاقة العقلية البسيطة.

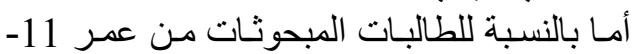

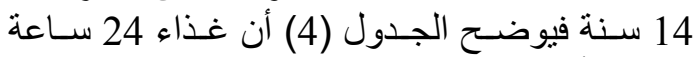
يمدهن بأكثر من احتياجاتهن الغذائية RDA في كل

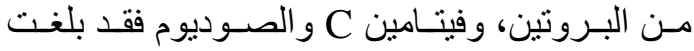


جدول (4): مقارنة متوسط الاستهلاك اليومي لأفراد العينة في عمر 14-11 سنة من العناصر الغذائية والطاقة

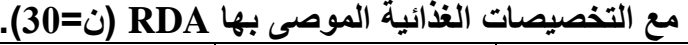

\begin{tabular}{|c|c|c|c|c|}
\hline $\begin{array}{l}\text { قيمة (ت) } \\
\text { t-value }\end{array}$ & 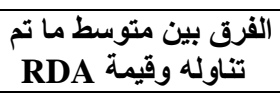 & قيمة التخصيصات الغذائية & متوسط ما تم تتاوله & العناصر الغذائية والطاقة \\
\hline 7.4- & 548.1- & 2200.0 & 1752.1 & طاقة (سعر) \\
\hline 6.0 & 18.7 & 46.0 & 64.7 & بروتين (جم) \\
\hline 0.6- & $9.0-$ & 275.0 & 266.0 & كربو هيدرات (جم) \\
\hline $9.8-$ & 25.6- & 73.3 & 47.7 & دهون (جم) \\
\hline $7.0-$ & $362.0-$ & 800.0 & 438.0 & فيتامين A (مكافئ ريتول) \\
\hline 4.7 & 54.5 & 50.0 & 104.5 & فيتامين C (ملجم) \\
\hline 7,7- & $0.4-$ & 1,1 & 0.7 & فيتامين B \\
\hline 1.3 & 0.3 & 1.3 & 1.6 & فيتامين B \\
\hline $12.2-$ & 687.0- & 1200.0 & 513.0 & كالسيوم Ca (ملجم) \\
\hline 0.6- & 44.0- & 1200.0 & 1156.0 & فسفور P (ملجم) \\
\hline $1.9-$ & $2.0-$ & 15.0 & 13.0 & حليد Fe (ملجم) \\
\hline 8.7 & 1000.3 & 500.0 & 1500.3 & صوديوم Na (ملجم) \\
\hline
\end{tabular}

دار البيـان العربـي، جـدة، المملكــة العربيـة

$$
\text { السعودية. }
$$

القحطاني، م. (1995م). تقييم الحالة الغذائية لطلاب المباب

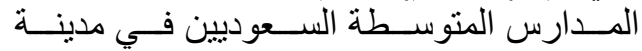

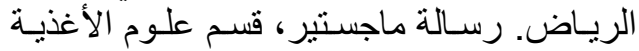

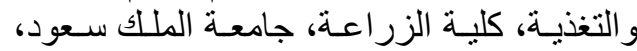

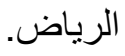

المعتــاز ، ف. (1988م). در اســـة الحالـــة الغذائيــة

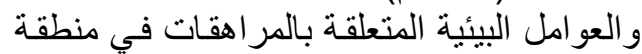

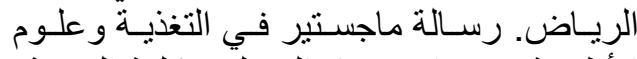

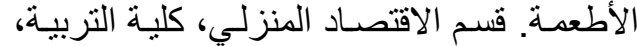
الرئاسة العامة لتعليم البنات، الرياض الرئ.

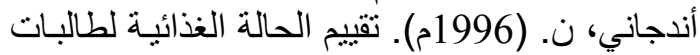

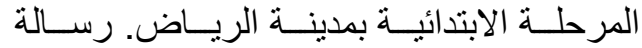

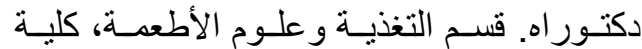
التربية للاقتصاد المنزلي، الرئاسـة العامـة لتعليم العيدة

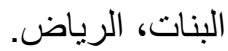

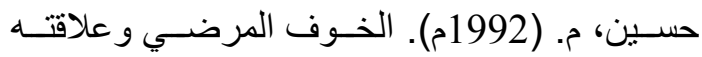

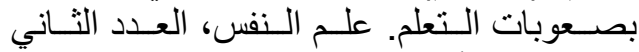

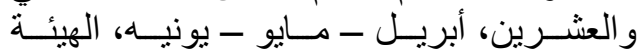
المصرية للكتاب.

عويضـة، ع. (1999م). تخطيط الوجبـات الغذائيـة. مطابع جامعة الملك سعود، الرياض.

Al-Saderi M.A. (1991). Nutrition Status Assessment of the Technical and Vocational Students. Community in Riyadh, Saudi Arabia. Ph.D. Thesis Liverpool Polytechnic School of Education and Community Studies, U.K.

\author{
5. 5. 5 5 التوصيات \\ من هذه النتائج التي توصلت إليها الدراسـة فإنـه \\ يمكن اقتر اح التوصيات النتالية:

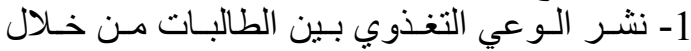 \\ الندو ات وحلقات النقاث لتعريفهن بكيفيـة أختيار \\ الوجبة الغذائية المتوازنة والني تقلل من السمنة \\ و النحافة. \\ 2- العمل على زيــادة المتنـاول من الطاقـة و الدهون

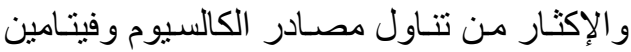 \\ A وفيتـامين B 1 و التقليـل مـن تنـاول البـروتين

$$
\text { ومصادر الصوديوم. }
$$

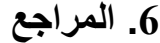

أبوزيد، ع. (2001م). تقييم الحالة الصحية و الغذائية البـة للأطفال ذوي الإعاقة العقليـة البسيطة (عمر 6- فل

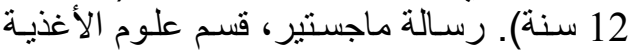

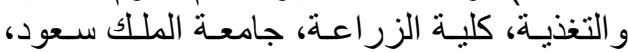

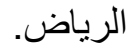

البدر، ن. (1994م). تقيم الحالـة الغذائيـة و علاقتهـا

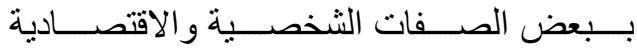

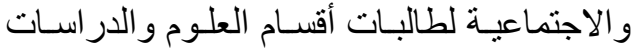

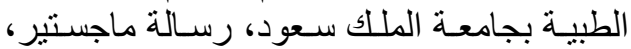

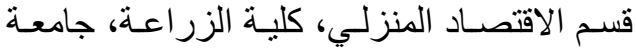

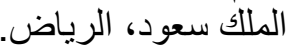
الروسـان، ف. (1998م). سيكولوجية الرياض الأطفال غير

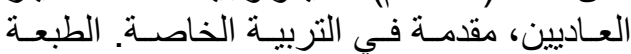

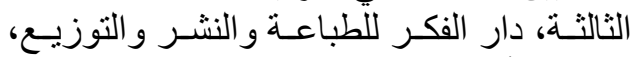

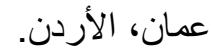
الثيمي، ن.، و المنياوي، م. (1988م). أسس التغذيـة وتقييم الحالة الغذائية، الطبعة الأولى، 
Al-Sekait M., Nasser A., and Bamgobye E. (1992). The growth pattern of school children in Saudi Arabia. Med. J. 2:141146.

Al-Shoshan A.A. (1990). Some sociodemographic factors influencing the nutritional awareness of the Saudi teens and adults: Preliminary Observations. J. R. Soc. Health. 110(6):213-216.

Chang K., Lee M., Low W., Chui S. and Chow M. (1965). Standards of height and weight of Southern Chinese Children. Fat East. Med. J. 1:101-109.

Eleanor N., Corine B., and Sharon R. (1991). Understanding Normal and Clinical Nutrition. West Publishing Company.

FNB NRC (Food and Nutrition Board, National Research Council). (1989). Recommended Dietary Allowances. 10 ${ }^{\text {th }}$ ed. Washington, D.C. National Academy of Sciences.

Frisancho A. R. (1993). Anthropometric Standards for the Assessment of Growth and Nutritional Status. Health produce (1988),2126 Ridge, Ann. Arbor, MI 48104.

Hamill P., Drizd T., Johnson C., Reed R., Roche A. and Moore W. (1979). Physical growth: National Center for Health Statistics Pereentiles. Am. J. Cl;in. Nutr. 32:607-629.
Hamilton E., Whitney E., and Sizer F. (1988). Nutrition Concepts and Controversies. Fourth Edition, West Publishing Company, New York.

Hammounda N., Abdel-Fattah M., Omar E., Lebshtein A., Wasfy A., and Higazi N. (1989). Effect of Parasitic infection on the nutritional status of school children in Jeddah \& Wadi Fatma, King Abdulaziz University Press, Jeddah, Saudi Arabia.

NRC. (National Research Council). (1989). National Academy of Sciences Recommended Dietary Allowances, $10^{\text {th }}$ ed. National Academy of Sciences, Washington, D.C.

Sayed N., Sally M., Khan M., and Andrew T. (1999). Biochemical hypothyroidism secondary to iodine deficiency is associated with poor school achievement and cognition in Bangladeshi children. J. Nutr. 128:980-987.

Sebai Z. (1984). The Health of Family in a Changing Arabia: A case of Study or Primary Health Care, $4^{\text {th }}$ ed., Saudi Arabia.

Wenlock R., Buss D., Moxon R. and Bunton N. (1982). Trace nutrients iodine in British food. Br. J. Nutr. 47:381-390.

Williams S.R. and Anderson S.L. (1993). Nutrition and Diet Therapy $7^{\text {th }}$ ed. Mosby Co., Boston. 